\title{
Algorithmic Culture, Networked Learning and the Technological Horizon of Theory
}

Mark Dawson

Lancaster University Management School, Lancaster University, Lancaster, UK mark.dawson@lancaster.ac.uk

ORCHID ID: https://orcid.org/0000-0001-7747-2768

\section{Biographical Note:}

Dr Mark Dawson is Director of Digital Education and a Senior Teaching Fellow at Lancaster University Management School. He is also a member of the Centre for Technological Futures, and Lancaster's Centre for Technology Enhanced Learning. His research background takes in Psychoanalysis, Continental Philosophy and Literary Theory, and is particularly interested in how, at the intersection of these diverse intellectual traditions, there is a critically unique engagement with technology. His current research reads that engagement in the context of higher education, and addresses the impact of digital technologies on academic identity and practice, particularly in terms of automation, surveillance and the organisational structures of the university. 


\section{Algorithmic Culture, Networked Learning and the Technological Horizon of Theory}

\section{Abstract:}

Going via Bernard Stiegler's theorisation of technology, and his response to Chris Anderson's claim that the era of hyper-networked, algorithmically-driven digital technologies signals the end of theory (Anderson, 2008), this paper aims to place the educational practice of networked learning as a space to think the edge, excess or limit of this proposed algorithmic dominance. I discuss how networked learning can negotiate the border between educational theory, the practice of teaching and learning, and the processes and systems of educational technology, but suggest that to do this it must engage these disciplines through a thinking of technology which does not decide upon its status in advance. I argue that affirming this particular relation to technology is increasingly urgent given we are at a moment in which educational institutions are asking how to prepare our students for an age of continuing technological disruption.

Keywords:

Bernard Stiegler; networked learning; algorithmic culture; higher education; algorithmic governmentality

\section{Introduction}

The 'digital turn' of the early 1990s saw the first stage of mass public internet access and the integration of digital networked technologies on a hyper-industrial scale. For the philosopher and cultural theorist Bernard Stiegler, such a period (a period marked by the introduction of platforms such as Amazon, Google and Facebook), prompted a series of ontological traumas from which we are yet to recover. This included what Stiegler has previously called 
'disorientation' (see Stiegler, 2009), which has now mutated to become a state verging on 'generalised stupefaction' (Stiegler, 2016, p. 25), and a certain widespread malaise. Stiegler suggests that such a generalised malaise is the result of an increasing shift to ever more sophisticated processes of automization as conditioned by networked digital technologies. When such technologies process data and provide responses at increasingly faster and faster speeds, the capacity to think is short-circuited, a tendency which, over time, slowly alienates an individual from the forms of knowledge which had previously been handed down and/or crafted over generations and across traditions. It is as a result of such a generalised state of alienation, or 'proletarianizing tendency' (Stiegler, 2016, p. 29), that Stiegler can both identify texts in which our capacity to theorise has begun to be questioned (Stiegler, 2016, p. 1), as well as himself appearing to endorse such a suggestion (Stiegler, 2016, p. 29). If these suggestions are correct, and the era of networked digital technologies has brought with it a generalised stupefaction which is also an erosion of our ability to think theoretically, then we are faced with a potential double-bind in which the network of platforms in which our everyday lives are - to a greater or lesser degree - embedded, are also the condition for the eradication of a capacity to think the impact of that very network. In other words, if we are to understand the potentially traumatic after-effects of such an overwhelming digital turn, we need to somehow reaffirm the very capacity to think before we succumb completely to the stunned paralysis from which thought may never recover.

In this short paper, then, I want to approach this double-bind through the question of technology and its use in education, and will do this through a particular re-positioning of technology which recalls both Stiegler's theorisation of technology and its indebtedness to deconstructive thought. I hope that this might give us space to re-affirm the possibility of theory as a certain pedagogical principle in higher education. Firstly, then, I will map the question of theory in the context of the 'algorithmic governmentality' as outlined by Thomas Berns and 
Antoinette Rouvroy (2013). This is a term to which Stiegler is indebted in his readings of digitally networked technologies, and can be aligned with some of the negative effects of mass automization. Indeed, Stiegler describes 'algorithmic governmentality' as the description of a 'new kind of economy' which is based on 'personal data, cookies, metadata, tags and other tracking technologies', and through which methods from applied mathematics are placed in the service of 'automated calculation' (Stiegler, 2016, p. 1; and: Berns and Rouvroy, 2013, p. 163 96). By situating algorithmic governmentality within what I will refer to as 'algorithmic culture', I want to highlight a potential response to its more detrimental effects, but one which is itself generated by the networked digital technologies through which algorithmic governmentality is played out. I do this because, somewhat inevitably, we have no other option but to accept the influence of the algorithm at every level, even in our attempts to think beyond it. It is for this reason that Stiegler's work is so important to the paper; his ongoing attempt to work with the conditions and effects of hyper-industrial digital economies in order to think beyond them resists the fantasy of a position which may pre- or post-date our essential relation to technics. It is because of this that I want to keep 'algorithmic culture' as the sign of the positive excess of its governmental counterpart; I want to think the edge, excess or limit of algorithmic governmentality from within algorithmic governmentality, with a view to explicating a particular reading of technology which is not reducible to the digital, and which in turn might help re-affirm a notion of theory as that which has always exceeded any algorithmically determined definition or, indeed, eradication.

The second strand of the paper will situate this argument in the context of higher education and consider a particularly niche area of academic discourse: networked learning. I focus on the latter because it is here that there seems to be a space for thinking through the relation between theory, technology and education at the very point at which networked learning is being cited as a space to address algorithmic culture (Jandrić, 2017). I will explore 
how, in its particular incarnation at Lancaster University, networked learning negotiates the border between educational theory, management education, and the practices and processes of (educational) technology, and I will conclude by suggesting how this particular instance of networked learning may offer an engagement with these disciplines through a horizon of technics which does not decide upon the status of technology in advance. I hope, then, that this paper will prepare the ground for a rethinking of the relationship between theory, technology and education at the very point at which educational institutions are asking themselves how to both respond to, and prepare our students for, an age of continuing technological disruption.

\section{I.}

It is no coincidence that the opening of Stiegler's Automatic Society, a text which considers the possibility of the social within the context of generalised automation, begins with a reference to Chris Anderson's Wired article entitled 'The End of Theory: The Data Deluge Makes the Scientific Method Obsolete'. In it, Anderson concludes that:

The new availability of huge amounts of data, along with the statistical tools to crunch these numbers, offers a whole new way of understanding the world. Correlation supersedes causation, and science can advance even without coherent models, unified theories, or really any mechanistic explanation at all (Anderson, 2008).

For Stiegler, the driving force behind theory is desire. In the citation above we can see Anderson aligning the substitution of ideals such as coherence, unification and explanation for the statistical manipulation of (big) data. Whether or not we share these ideals, the point for 
Stiegler is that 'the desirable in general is what consists' and such 'consistencies' are also the object of theory. The practice of theory, therefore, equates to the desire for certain consistent objects, and for Stiegler, such consistencies, 'in the psychic and collective individuation that constitutes the polis', are presented as:

- $\quad$ the just, which does not exist, but the idea of which is practically managed and conserved by law, which prescribes social ways of living in common, and promises a livable and polite [poli], if not actually just, world;

- the true, of which geometry, in the Western experience of rationality, is the matrix and the canon, constituted through the ideality of the point, which does not exist, but which trans-forms the world through being contemplated theoretically, and through the practical consequences of this contemplation;

- the beautiful, which is improbable, as Kant said, that is, unprovable, and as such 'imaginary' and 'dreamed', allowing us to dream, but which, experienced by the subject who judges aesthetically, puts to the test the singularity of his or her judgement and the object of this judgement, allowing this subject to individuate him-or herself and to do so as this dreamer - sometimes to the point of becoming an artist (Stiegler, 2018, p. 43-4).

With an eradication of theory comes the eradication of the consistencies outlined above. It is clear, then, that much is at stake with the suggestion that the death of theory might also mean the death of such things as the ability to think, dream and individuate the law, truth, and the beautiful (as the very possibility of thinking the unprovable or even unthinkable). For Stiegler, 
because 'the objects of such consistencies [law, truth and beauty] are also those of theories, the latter presuppose the learning and apprenticeship of affective and erotic idealization [... consequently] when the libidinal economy lies in ruin, so too does theory' (Stiegler, 2018, p. 44). From this, we can suggest that a society in which theory has been erased would equate to one in which desire (as 'effective and erotic idealization') has also been ruined. Theory requires the erotic idealization of consistencies such as the law, truth and beauty. Moreover, it is almost certainly the case that one of the best opportunities to develop a relation to idealized consistencies is through the apprenticeship into disciplinary thinking which is gained through tertiary education. In turn, we can now see how an eradication of the capacity for theoretical thinking would also provide the conditions for a diminished notion of what the intellectual life of the individual might be.

At the same time, however, and as indicated above, the information and communication networks upon which the statistical manipulation of big data and subsequent 'death of theory' is predicated, are the same networks which must pave the way for a reaffirmation of the consistencies upon which theory depends. This recalls the pharmakological logic at the heart of all technology, which in a now familiar reading made by Jacques Derrida in 'Plato's Pharmacy' (Derrida, 1981, p. 61-171), we are alerted to the fact that Plato represents the

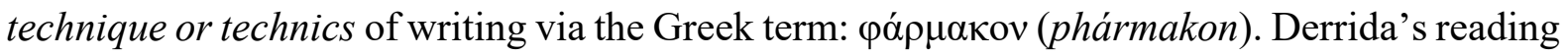
highlights that this term, which can signify a charm, philtre, drug, remedy, poison, potion or spell, renders a notion of technics as that which can have both poisonous and remedial effects. Derrida also outlines how the technics of orthographic inscription were described in these terms, and then maps some of the profound implications. In doing this, he makes a crucial reading of the pharmakon which, despite its familiarity in contemporary critical thought on (digital) technology, has not been followed through to its most radical implications: 
The pharmakon has no ideal identity; it is aneidetic, firstly because it is not monoeidetic (in the sense in which the Phaedo speaks of the eidos as something simple, noncomposite: monoeides). This 'medicine' is not a simple thing. But neither is it a composite, a sensible or empirical suntheton partaking of several simple essences. It is rather the prior medium in which differentiation in general is produced [my italics] (Derrida, 1981, p. 126).

If the pharmakon describes the medium in which the play of difference is produced, indeed where such difference can't be halted, then we can begin to see why such a dangerous supplement can be damaging to any attempt to delineate a stable definition of technology, or that which it is said to condition (i.e. the end or death of theory). In other words, because technology is always referring to this prior medium as the very possibility of differentiation, then it is also impossible to say exactly what a certain form or deployment of technology can or cannot do, or what it will or will not lead to. As the medium in which difference is produced, it is by definition the very possibility of a relation to the future as that which remains unknown.

Referring to our argument above, this means that the technological milieu which sees the reduction of individuated desire to its manufactured, calculable and therefore marketable substitute, might also be that which can stimulate it. For Stiegler, this means that to get thought thinking again we must be able to 'think algorithmic governmentality within algorithmic governmentality' (Stielger, 2016, p. 128), which is to say that, as we are always-already immersed in the project of algorithmic governmentality, we must somehow turn it against itself by using it as the condition for a new concept and articulation of educational practice which can somehow outrun the 'generalised proletarianisation' which is at the heart of our current situation: 
Historically, proletarianization was the loss of workers' knowledge to machines, which absorbed this knowledge. Today, proletarianization is the standardization of behaviours through marketing and services, and the mechanization of minds through the externalization of knowledge in systems, such that these 'minds' no longer know anything about these information processing devices, of which they merely set the parameters. This is precisely what the electronic mathematization of financial decision making shows, and it affects everyone: employers, doctors, designers, intellectuals, leaders. More and more engineers take part in technical processes whose functioning they know nothing about, but which are ruining the world (Stiegler, 2011; quoted in Berns and Rouvroy, 2013).

As Stiegler has consistently and convincingly argued, the algorithmically driven capture of the capacity for noetic activity is the latest stage in the proletarianisation of human life by technological development, a phase which began with the "submission of the body of the labourer to mechanical traces inscribed in machines' (the proletarianisation of workknowledge), and which went on to capture 'life-knowledge' through the analogue traces of technologies such as television and broadcast media in general. Such knowledge is proletarianised because, like the subsumption of the worker's skills, techniques and knowledge into the machine that will automate and reproduce that know-how ad infinitum, analogue and digital technologies have perfected that process by which intellectual activity has been shortcircuited but the capturing of attention. In this sense, desire is now manufactured en masse and transmitted to individuals through marketing and advertising techniques, as opposed to its slow growth and nurturing via the contemplation of consistencies that an apprenticeship in 
disciplinary thinking would introduce. Desire, then, (if we can still call it that) is produced for the people, rather than it being a product of the people. Part of the task in hand, then, is the rebuilding of social, cultural and political milieux as spaces for the nurturing and caring for intellectual activity; an intellectual activity which is driven by a notion of desire which is defined by the very consistencies which it seeks.

I want to argue that this places theoretical thinking - which depends upon a desire for consistencies such as the law, truth and beautiful - as central to this rebuilding. What is more, such a positioning of theory must embrace the hyperindustrial networks of digital technologies which connect everyone and everything and which provide the conditions for the reduction of thought to calculable, efficient and ultimately profitable data, and turn them on their heads into spaces for the de-proletarianisation of noetic life. This is the space of an algorithmic culture that, through the pharmacological medium of differential technics, exists within the governmentality of the networks only in order to exceed that calculable realm. By referring to this as the chance of algorithmic culture, I want to name that opportunity for thinking algorithmic governmentality otherwise, an opportunity to affirm a future which isn't calculable or determined in advance, and which is the very condition of the consistencies upon which theory is based. In this sense, technics becomes a horizon for a theory which cannot be determined as living or dead. It is therefore impossible for any particular technology (whether digital or not) to eradicate the capacity to think theoretically when that thinking is directed towards, and conditioned by, a future which is irreducible to algorithmic prediction. In the final section, then, I will try to demonstrate how this can be considered a little more pragmatically through the practice of networked learning. I want to suggest that it is here that we might affirm a horizon of technics which does not decide upon the status of technology in advance, and that it is because of this particular theorization of technics that we can begin to think an educational practice fit for the age of algorithmic culture, as opposed to a practice that is determined in 
advance by the calculable economies and ubiquitous surveillance and tracking technologies of algorithmic governmentality.

\section{II.}

Referring to 'algorithmic governmentality' as 'the thoroughly computational capitalism that is establishing an era of absolute non-knowledge' Stiegler begins to outline the 'associated milieu' which conditions such an era:

In this absolute non-knowledge, knowledge itself disintegrates into the information generated by fully automated calculation, and into fixed capital, which, along with 'big data', forms the hyper-synchronized associated milieu [...] produced by the applied mathematics of correlational algorithms. In this hyper-synchronised milieu, the diachronic can no longer exteriorize itself other than diabolically, that is, outside of any circuit of transindividuation, or in other words, outside of any synchronic metastability (Stiegler, 2017).

This particularly negative milieu is also referred to by Stiegler as the 'Digital Leviathan' (Stiegler, 2016), or, as Ross Abbinnett suggests, an 'arche-programme': 'that is, a totality of systems each of which develops in relation to a universal principle of efficient transfer of knowledge, information and value'; 'the system of discrete modalities of digital representation and manipulation that simultaneously analyse, anticipate and synchronize the production of libidinal energy' (Abbinnett, 2018, p. 8 \& 40). What all these definitions have in common is a 
networked environment, but one in which Stiegler seems to read a certain nuanced and ambiguous quality:

There is no "territory" without a network; there is always only a network, as framework: territory's simple unity is mythical [...] The fact that the territory is already framed, that it is nothing other than the network-to-come, does not mean that the conditions for such a framing are always the same; it occurs within a particular typology and a general history of such conditions $[\ldots]$ The materialization (objectification) of such frameworks is also the dynamic of their alienation or de-realization; their exteriorization. Networks affect and disaffect, organize and disorganize rhythms and memories. The network is in this sense programmatic. (Stiegler, 2009a, p. 144; cited in Abbinnett, 2018, p. 50)

The network is programmatic, but according to an inherently ambiguous, or pharmakological, logic. It is this phenomenon of the network, by which it (dis)organises and (de)realises the dynamic of everything that is (dis)connects, that I want to emphasise when we look at the notion of networked learning as both a pathway for the intensification of calculable thought, as well as the possibility of its excess.

In a now familiar but useful definition, networked learning can be thought of as 'learning in which information and communications technology (ICT) is used to promote connections: between one learner and other learners; between learners and tutors; between a learning community and its learning resources.' (Goodyear, Banks, Hodgson, \& McConnell, 2004, p. 1). Looked at through a pharmakological lens, I would argue that the resulting effect of a networked learning would be to make all these categories tremble, and yet this particular 
phenomenon of a networked approach to learning can easily be overlooked. In his 2015 text on networked learning, Chris Jones provides a useful overview of the theoretical genealogy of the network (Jones, 2015, p. 79). In the title of this section - a 'Network of Network Theories' Jones, perhaps somewhat unwittingly, gives us an image of the network as the very thing which puts its conceptual determination into question. That is, the ambiguous logic of a networked series of definitions provides a programmatic (dis)aggregation or (dis)assembling of any kind of self-contained conception of the network. As there is no one concept of the network, neither the network, nor that which is produced through it, can be reduced to a calculable quantity, be it a discipline, an identity, an outcome, a position or an intention. It seems to make sense, then, to suggest that the potential of higher educational practice to perform a critique of, or response to, algorithmic governance lies in its ability to somehow maintain the paradoxical network effects outlined above. In other words, in an age of networked digital technologies, most of which now seem to be put to work to install some kind of algorithmic governmentality, higher education also needs to operate under the same networked conditions and become something which can think or critique this position from within. Some form of 'networked' learning seems well positioned to perform such an operation, but if it is to somehow organise the disorganisation of the calculable, or work towards consistencies which are not immanent to a calculable end-point of learning (what might also be thought of as a learning with and from the other), then it must also affirm, and work with, the often unacknowledged (in)determinacy which is at its heart.

Indeed, Jones does himself get some way to suggesting that networked learning, if it is to work towards some of its more socially engaged themes, must begin to makes those themes a little more apparent: 'networked learning has rarely engaged with the broader political landscape $[\ldots]$ and this is becoming a more pressing concern in the current global recession because of the severe pressures placed on higher education by economic conditions' (Jones, 
2015, p. 42). My concern, as outlined above, is that such an engagement would require a fairly radical shift in the way that networked learning theorises the technology which is core to it. One of the attractions of networked learning has always been the inability to truly define itself (something which Jones' text implicitly evidences). It seems no coincidence that such indeterminacy is inherent to a form of educational or academic practice which has the notion of the network at its very heart. For me this is because the actual technics of the network has an 'essential' relation to the pharmakological medium of difference which Derrida saw as the very (non)essence of technology. This is why, in an interesting distinction between social networks and a network society, Jones can state that: 'network society cannot be reduced to either networks or to social networks, because both networks and social networks have long histories which predate digital technologies (Jones, 2015, p. 37). I would take this a little further to suggest that the network predates the social in that, as a medium of difference, it becomes its very condition. In other words, the social is always a certain effect of technics, but of a generalised or originary technics, the dynamic or economies of which the notion of the network will always be inscribed. ${ }^{1}$

In a recent chapter, Petar Jandrić has also come close to Jones' call for a more socially engaged instance of networked learning. When discussing the potential for a 'critical' networked learning to be linked to transdisciplinary and/or multidisciplinary modes of working, he states:

Disciplinarity, multidisciplinarity, and interdisciplinarity are imbued within the existing social and technoscientific orders. In spite of significant epistemological and practical achievements, therefore, these methodological

\footnotetext{
${ }^{1}$ For a particularly useful exploration and explanation of 'originary technicity' see: Bradley, 2011.
} 
approaches are structurally unable to provide radical social change. Transdisciplinarity and antidisciplinarity are better suited for critical networked learning, as their position outside of dominant disciplinary power relationships provides genuine potential for emancipation and social transformation (Jandrić, 2016, p. 178).

Although I am not certain that the prefixes 'trans' and 'anti' do enough to avoid the structures and power relationships that Jandrić suggests they might, not least because the very notion of the network would make that move impossible to fully complete, Jandrić does associate a radical emancipatory potential with a criticality that networked learning could generate. Such a combination would, however, require us to remain within existing social and technoscientific structures in order to think them at their limit. For Stiegler, this would require us to put the network to work in such a way as to combat the hyper-synchronicity in which a fully calculable world would result. A thinking which could both comprehend, and think beyond such a milieu would be one which situates diachronicity within Stiegler's 'circuit of transindividuation'. Providing the conditions for such a circuit is a role that a critical networked learning might play; embedding a critical practice within a circuit which resurrects the desire for the thinking of consistencies across time, would allow us to both work within and beyond our increasingly hyper-synchronised milieu.

A networked learning which encourages this would, however, require a relationship to technology which does not reduce that term to a description of a mechanism for achieving aims decided elsewhere. Instead, such a relationship would affirm a certain generalised technological horizon of an educational practice which does not seek to delimit or define technology within that horizon as something which can be added or removed at will, according 
to prior, predestined and/or calculable goals. Such a relationship would also prevent us from privileging the more reductive but familiar interpretation of technology as simply the more efficient cure to a flabby, outdated (educational) system. At this point then, we might argue that we should refer to this generalised horizon of technology by the Greek term tekhnē. This term, which is the etymological foundation to the word 'technics' and thus 'technology', also recalls a prior definition which relates to an art, craft or skill. Derrida's reading of the pharmakon, however, which begins to bring a thinking of technology into alignment with the medium in which difference is produced, suggests that even tekhne is a fairly strict delimitation of a dimension which will always exceed it. But by affirming this quasi-originary dimension (which is 'quasi' because it can never actually be reached or thought other that in its more particular, material or empirical exemplars) as the horizon of a new form of educational practice, and one that a critical networked learning might embody, we might also approach the conditions for a new relationship to knowledge, and to what Stiegler - following Foucault refers to as 'the era of a new epistemèe' (Stiegler, 2017, section 4). This would, in turn, go some way towards preparing the ground for Peter Goodyear and Lina Markauskaite's more pragmatic call for tertiary education to show leadership in the area of 'epistemic fluency' (Goodyear \& Markauskaite, 2018), and my own extension of this towards something that might be termed ‘epistemic health’ (Dawson, 2019).

\section{Discussion:}

To take us towards some concluding remarks, I want to briefly describe a specific project which encourages a networked learning approach to teaching and learning practices at Lancaster University, and more precisely a particular effect of this approach on academic identity. The project's aim is to encourage academic staff to develop their teaching practice alongside a 
network of fellow academics, professional service staff and students, and which has so far resulted in a series of experimental teaching interventions. As the project is situated within the practice of networked learning, there is a focus on the use of digital technology within the planning, design and deployment stages of the project, and particularly as the University's VLE provides the central method of organising the project in terms of regular communications between participants, sharing of notes/ideas, drafts etc. But the project does not have an imperative for participants to embrace digital technology uncritically in their teaching practice. Indeed, one outcome of the project is that it formed a space to critique the call for more online and blended approaches. A further, and to some extent, unexpected outcome of the project was the formation of a smaller group of participants who wanted to think through their experiences of taking part, and particularly the shared sense of dislocation which the introduction of more technologically augmented teaching methods had provoked. What was in question, then, was identity of the academic, and in the following passage, a certain 'loss of presence':

The 'loss of presence' occasioned by the shift to networked learning, and the need to develop a 'new disembodied identity' (Hanson, 2009, p. 561) which thus arises require the adoption of new roles by academics. When students become 'discoverers and constructors of knowledge' (Hartman, Dziuban and Brophy-Ellison, 2007, cited in Hanson, 2009, p. 556) then academics must become 'co-discoverers' and 'co-constructors' and accept the seeming loss of expert status which this implies (Iszatt-White, 2018, p. 6).

All of the phrases used above to describe the changes in academic identity which a particular instance of networked learning has encouraged, can, I would argue, be considered the effects 
of a further shift in the notion of technology which the move to a networked learning approach has encouraged. Somewhat ironically, however, it was also the fact that as the project adhered to a networked learning approach, the staff involved found both the urgency, and the means, to reformulate and reflect upon their experience. In this sense, the practice of networked learning, and the greater emphasis placed on technology as the condition of the project's deployment, has conditioned both the disorganisation and reorganisation of an academic identity, but with the latter becoming a less calculable and/or less stable phenomenon than that which may have been traditionally experienced.

It is important to remember that such a displacement of academic identity has always has the potential to occur; the project in discussion has merely up-fronted what is usually either repressed, denied or displaced by other more forceful or influential academic performances or identities. But a key point to take from Iszatt-White's suggestion, is the notion of a 'loss of presence' or 'disembodied identity' which she could identify as a direct consequence of a shift to networked learning and teaching practices. This is not to be overlooked given the huge weight the notion of presence has had, and continues to have, in what is too easily described by the phrase 'Western culture', and in turn in the academic imaginaries which can be played out within that culture. I would argue, then, that the seemingly explicit loss of presence which is felt here is in fact a more conscious echo of a generalised network effect, and one which again touches on the originary pharmakological dimension Derrida pointed us towards. As deconstruction has continued to demonstrate, the notion of presence is always a fantasy constructed after the fact, and one with which the founding meta-philosophical notions of western culture have been intimately related. What Iszatt-White has experienced, then, is an up-fronting or making explicit of something which is always-already at work: the impossibility of presence as a stable concept. It is interesting, however, that it has taken a shift in pedagogic approach (to one which emphasises a networked learning) that has allowed the academic to 
reflect upon this phenomenon, and to begin to address/affirm it. What might at first be seen as a fairly casual remark, then, is in fact something very radical; it is also potentially empowering, because that loss of presence comes hand in hand with a greater level of unknowability, an unknowability as incalculable element which is also the very possibility of thinking otherwise. What Iszatt-white has highlighted, then, and perhaps inadvertently, is the capacity for the practice of networked learning to engage a little more intimately with the quasi-originary medium of technological differentiation as the ground for re-thinking what educational practice and academic identity might be.

A caveat to add to this, however, is that the reorientation in our relation to technology which is necessary if we are to affirm considered and rigorous teaching and learning practices in the age of industrial scale networked technologies, also opens the door to further threats to academic life; namely: precarity, mass surveillance and tracking, and perhaps less explicitly, a conflicted narrative as to the future and purpose of higher education. Indeed, as another participant on the networked learning project has anecdotally related, the lack of clear and legitimate reasoning as to the rationale for participating in such a project can quite easily be attributed to the inconsistencies regarding the intuitions' strategic objectives in terms of its relation to, and incorporation of, digitally informed learning and teaching practices. Why, for example, should an academic whose career progression often hinges upon relating strong research to a consistent and stable identity, risk that hard-earned legitimacy by focussing on specific teaching practices which might undermine it?

\section{Conclusion}

In considering a relation to technology as a more general dimension, a relation which a shift to networked learning practices can make more apparent, we are offered a chance to encourage 
the construction of theoretically-informed knowledge within networked digital economies. We have seen how Stiegler's reply to Anderson's proposition that such technological evolution brings theoretical work to an end, involves a reaffirmation of the consistencies at the heart of critical and theoretical work, but that this reaffirmation must somehow take place within the very networks which seem to be eroding it. I have echoed Stiegler's suggestion, but at the same time made explicit that such a task must engage at a certain level the quasi-originary or pharmakological dimension of technology which, as Derrida shows, can be read as the very medium in which difference, and therefore otherness, is produced.

What is important to stress, however, is that it is impossible for anyone, including Anderson, to say once and for all where theory must begin or end, or live or die. And this is precisely because even the largest data sets, and the most powerful of processing capabilities, or the most stable of concepts (including that of 'theory') will always be exceeded by the differential medium in which that data, or those processes are inscribed. Such a medium means that there is always a beyond or excess of data in relation to which such data is always-already constituted, and that this relation is very chance of thinking differently (we might say that, if there is to be such a thing as theory, then this is its space or chance). Admittedly, such suggestions require extensive further work, both in terms of a rigorous deconstruction of all that is being too briefly alluded to here, including a detailed reading of what such a deconstruction would mean for the more practical realties of everyday academic life. With regards to the latter, I have suggested that a specific pedagogy, networked learning, might help us mediate the implications of this more radical reading of technology, and to do this in the particular economies and locales of our everyday academic commitments. Although we are not quite at the bleeding edge of a new form of academic endeavour, or yet achieved the reorientation of our relations to technology, neither should we take such small steps for granted. Rather, I want to propose that this paper acts as an indication of how we might begin, through 
affirming the ambiguous effects of the network, to think learning and teaching practice at the limit, and to perform it otherwise, whilst remaining within the social and technoscientific orders which that very affirmation may yet have the capacity to transform. 


\section{Bibliography:}

Abbinnett, R., (2018). The Thought of Bernhard Stiegler: Capitalism, Technology and the Politics of Spirit, New York: Routledge.

Anderson, C., (2008). 'The End of Theory: The data deluge makes the Scientific method Obsolete', Wired, https://www.wired.com/2008/06/pb-theory/

Aristotle, (1979). Physics, Book 2, Oxford: Oxford University Press.

Berns, T., and Rouvroy, A., (2013). 'Gouvernementalité algorithmique et perspectives d'émancipation', Réseaux 1 (177), pp.163-96. [Accessible at: https://www.cairnint.info/article-E_RES_177 0163--algorithmic-governmentality-and-prospect.htm]

Bradley, A., (2011). Originary Technicity: The Theory of Technology from Marx to Freud, London, Palgrave Macmillan.

Dawson, M. (2019). 'Towards Epistemic Health: On Stiegler, Education and the Era of Technological Unemployment', in: Jandrić, P.; Means, A. J.; Peters, M. A.; (Eds.), (2019). Education and Technological Unemployment. Springer

Derrida, J., (1981). ‘Plato's Pharmacy', trans. Barbara Johnson in Dissemination, London: The University of Chicago Press.

Goodyear, P; Banks, S.; Hodgson, V.; McConnell, D., (2004). Advances in Research on Networked Learning, Boston; Springer.

Goodyear, P.; Markauskaite, L. (2018). 'Universities Should Take Stronger Leadership on Knowledge and How it matters', The Conversation https://theconversation.com/universitiesshould-take-stronger-leadership-on-knowledge-and-how-it-matters-89849, (April 6, 2018). 
Iszatt-White, M., (2018). 'No more 'sage on the stage'? Networked learning and educator 'identity undoing'; development paper submitted to the British Academy of Management conference 2018 .

Jandric, P., (2016). 'The Methodological challenge of Networked Learning: (Post)disciplinarity and Critical Emancipation', in: Ryberg, T; Sinclair, C.; Bayne, S.; de Laat, M., (2016) Research, Boundaries, and Policy in Networked Learning, Switzerland; Springer.

Jandrić, P., (2017). 'Learning in the age of algorithmic cultures', seminar given at Lancaster University, https://youtu.be/md_HKiZu5c8 (accessed 21/12/2017).

Jones, C., (2015). Networked Learning: An Educational Paradigm for the Age of Digital Networks, Switzerland, Springer International Publishing.

Roberts, B (2012). Technics, individuation and tertiary memory: Bernard Stiegler's challenge to media theory. New Formations, 77 (1).

Stiegler, B., (2009a). Technics and Time Vol. 2: Disorientation, trans. S. Barker. Stanford, CA: Stanford University Press.

Stiegler B., (2011). “'Le grand désenchantement'. Un entretien avec le philosophe Bernard Stiegler", Le Monde, 21 February.

Stiegler, B., (2016). Automatic Society, vol. 1: the Future of Work, Cambridge: Polity.

Stiegler, B., (2017). 'What is called Caring? Beyond the Anthropocene', trans. D. Ross, Techné: Research in Philosophy and Technology, December 8, 2017. 